Filosofia

\title{
Alamedas
}

\section{A NOÇÃO DE PENSAMENTO EM DESCARTES}

\author{
Livia Tainan Nicolini Ruiz ${ }^{1}$ \\ Geder Paulo Friedrich Cominetti ${ }^{2}$
}

\begin{abstract}
RESUMO: Neste artigo, procuramos introduzir o leitor às noções imprescindíveis para a compreensão da noção de pensamento em Descartes. A noção marca o modo de pensar do ocidente, mas, embora seu nome tenha sido popularizado, sua filosofia é reproduzida com desfalques significativos por reiteradas vezes. Tem seus elementos tratados superficialmente ou é contemplada por extensas discussões que se dedicam a meandros técnicos alcançados apenas por especialistas. Em ambos casos, notamos nisso um problema. Sendo uma filosofia que serve de gênese a toda discussão que a sequenciou, a clarificação de seus elementos imprescindíveis é um ganho ao âmbito acadêmico e popular. Por isso, tematizamos a noção de pensamento - noção central à sua filosofia - a partir das Meditações, obra capital da metafísica cartesiana. Nossa metodologia, entretanto, visa recorrer também ao Discurso do Método, às segundas objeções e respostas - um apêndice do texto original das Meditações - e à primeira parte dos Princípios da Filosofia. Queremos entregar ao leitor um espectro fiel à coerência a obra como um todo. As Meditações trazem concepções implícitas, que tais obras elucidam com propriedade. Ao final, concluiremos quais os elementos indispensáveis à noção de pensamento em Descartes e daremos uma compreensão rigorosa e abrangente da noção em tela.
\end{abstract}

Palavras-chave: Filosofia moderna; Racionalismo; Descartes; Pensamento.

\section{THE NOTION OF THINKING IN DESCARTES}

\begin{abstract}
In this article, we seek to introduce the reader to the essential notions for understanding Descartes' notion of thought. The notion marks the way of thinking of the West, but, although its name has been popularized, its philosophy is reproduced with significant embezzlement again and again. Its elements are treated superficially or it is covered by extensive discussions dedicated to technical intricacies reached only by specialists. In both cases, we notice a problem in this. As a philosophy that serves as the genesis of all the discussion that followed it, the clarification of its essential elements is a gain for the academic and popular spheres. Therefore, we thematized the notion of thought - a central notion to his philosophy - from the Meditations, the capital work of Cartesian metaphysics. Our methodology, however, also seeks to resort to the Discourse on Method, the second objections and answers - an appendix to the original text of the Meditations - and the first part of the Principles of Philosophy. We want to deliver to the reader a spectrum faithful to the coherence of the work as a whole. The Meditations bring implicit conceptions, which such works properly elucidate. At the end, we will conclude which elements are indispensable to the notion of thought in Descartes and we will give a rigorous and comprehensive understanding of the notion in question.
\end{abstract}

\footnotetext{
1

${ }^{2}$ Docente efetivo no IFPR. Doutorando em filosofia Unioeste. Advogado (OAB/PR 83.393). Especialista em EAD. E-mail: geder.cominetti@ifpr.edu.br
} 
Keywords: Modern Philosophy; Rationalism; Descartes; Thought.

\section{INTRODUÇÃO}

Descartes é considerado o pai do racionalismo moderno porque fundamentou a origem do conhecimento na razão humana. Previamente, podemos entender a razão humana como sendo a capacidade operatória dos raciocínios. É a capacidade de o homem apreender conteúdos ordenados que lhe sirvam para a constituição do conhecimento. $\mathrm{O}$ funcionamento da razão humana, seus elementos, sua natureza e seus limites são tema caro à filosofia de Descartes.

Quando estudamos a obra de um autor, precisamos localizar o sentido dos termos que ele se utiliza. No caso de Descartes, a noção de pensamento deve ser tomada pelo leitor em um sentido estrito, i.e., não tomamos o conceito de pensamento em Descartes como o encaramos na lida cotidiana. Em Descartes, em sua obra, a noção de pensamento denota o operar do pensamento dedicado à constituição do conhecimento, v.g., do pensamento hoje dito científico. Num sentido lato, entenderemos o pensamento científico como o pensamento capaz de produzir conhecimento duradouro e confiável nas mais diversas áreas do saber humano.

A ciência da época de Descartes estava descreditada porque seu desenvolvimento tinha forte influência política. À época de Descartes, só se podia proceder cientificamente consultando os textos de Aristóteles ou os textos tomistas. Qualquer contradição a eles era vista como uma afronta aos princípios cristãos, defendidos como verdades absolutas pela igreja. A modernidade é caracterizada então por uma crise do proceder científico. Os instrumentos desenvolvidos permitiam melhor observação dos fenômenos da natureza, e os fatos que contradiziam as verdades absolutas ganhavam cada vez mais voz e vez no cenário da ciência. Inobstante, os quase dez séculos de domínio político do fazer científico pela igreja fizeram com que a verdade, antes de ser revelada, precisasse estar garantida por métodos eficazes. $\mathrm{O}$ grande tema do pensamento ocidental da modernidade foi, então, a discussão do método.

O método cartesiano é exclusivamente racional. Como dissemos, o que faz de Descartes um racionalista é o fato de ele fundamentar o conhecimento na razão humana. Seu método pressupõe a evidência dos objetos, a análise do elemento investigado, a 
REVISTA ALAMEDAS

Vol. 9, n. 2, 2021

e-ISSN 1981-0253 ordenação desses elementos para entender como se concatenam e a enumeração das etapas realizadas. Ao aplicar seu método ao conhecimento, Descartes desenvolverá a noção de pensamento como evidente, pois é o pensamento que não pode ser suprimido de qualquer conhecimento sem que tal conhecimento não seja também suprimido. É o pensamento que conhece. O pensamento humano sustenta o conhecimento. Partindo dessa evidência, uma análise do conhecimento passa a ser feita por Descartes, e tais elementos dele desmembrados é o que pretendemos desenvolver ao longo do texto que segue. Esperamos que, ao final, o leitor possa identificar a noção de pensamento em Descartes como característica principal do homem, base e centro do conhecimento; possa compreender as noções que lhe são elementares; possa tratar com propriedade de alguns temas concernentes a críticas ou a desenvolvimentos da filosofia de Descartes.

\section{DÚVIDA METÓDICA E COGITO}

Como racionalista, Descartes entende a natureza do conhecimento como sendo racional. Tendo a razão como parâmetro do conhecimento, ele a aplica às bases de todo conhecimento de sua época. A filosofia aristotélica e o tomismo fundamentavam o conhecimento nos sentidos humanos, pois acreditavam que daí vinham os primeiros “materiais" para a produção do conhecimento. Quando Descartes aplica a razão sobre os fundamentos do conhecimento de sua época, ele o faz por meio de uma postura cética quanto a esses fundamentos. Arquiteta com a razão uma dúvida artificial, chamada dúvida metódica radical de caráter hiperbólico (cf. GUÈROULT, 2016, p.35 e ss.) ${ }^{3}$. É metódica porque trata de um meio para chegar a um fim: ela é instrumento para alcançar a verdade; é radical porque mira o fundamento dos conhecimentos da época, atacando regiões desse conhecer: primeiro os sentidos, depois o próprio corpo que está à base dos sentidos, depois as próprias formas gerais dos corpos. A dúvida se diz de caráter hiperbólico porque exagera em seus argumentos, como veremos a seguir.

A dúvida metódica é dividida em três graus: o grau dos sentidos, o grau dos sonhos e o grau do deus enganador (cf. FORLIN, 2004, p. 18 e ss.). Todos esses graus estão sustentados pelo princípio de que tudo o que já nos enganou alguma vez deve ser rejeitado

\footnotetext{
${ }^{3}$ Como o intuito de nosso artigo é o de publicizar o pensamento cartesiano a um público não especialista em Descartes, sempre que possível, indicaremos as referências de textos em português ou em espanhol para facilitar o aporte aos temas de interesse do leitor.
} 
REVISTA ALAMEDAS

Vol. 9, n. 2, 2021

e-ISSN 1981-0253

como falso. A partir daí, o primeiro grau é determinado pelo seguinte argumento: os sentidos já nos enganaram, portanto, não devemos tomar os sentidos como base da verdade (cf. DESCARTES, 2018, p. 23). O segundo grau dita o argumento dos sonhos: já fomos enganados, enquanto dormíamos, de que éramos um corpo vestido e em movimento quando, depois acordando, percebíamos que estávamos dormindo nus. Portanto, por termos já sido enganados quanto a nosso corpo, não podemos tomá-lo como base indubitável da verdade (cf. DESCARTES, 2018, p. 25). O terceiro grau da dúvida é o que ingressa na hipérbole, porque exagera em sua argumentação. $\mathrm{O}$ argumento é dividido em duas etapas: deus enganador (cf. DESCARTES, 2018, p. 29) e gênio maligno (cf. DESCARTES, 2018, p. 31).

O argumento do deus enganador é o seguinte: como saberemos que deus nos fez de modo a conhecermos a verdade? E se nossa natureza é tal que jamais alcançaremos a verdade sobre as coisas? Ora, a ciência já mostrou tantas e tantas vezes como o homem pode errar em crenças tão convincentes que é mesmo possível não termos o conhecimento da verdade, mas sempre alcançarmos apenas uma verossimilhança do real. E, como não conseguimos sair desse problema, Descartes coloca uma segunda etapa ao argumento: a etapa do gênio maligno. Ela se formula do seguinte modo: como não sei se fomos feitos de tal modo que jamais conheceremos a verdade acerca da realidade das coisas, então vamos pressupor que há um gênio maligno a nos enganar toda vez em que pensamos estar certos de algo. Tudo o que acreditamos até agora, foi um artifício embusteiro desse gênio maligno. Acreditando que fomos enganados sempre e que não podemos reconhecer a verdade, não cairemos em erro se uma verdade qualquer surgir porque ela precisará anular o argumento do gênio maligno. A hipérbole da dúvida metódica se dá no exagero de rejeitar qualquer verdade trazida pela cultura ou pelos meios até então frequentados, fazendo com que a verdade seja buscada em um terreno ainda inexplorado. A verdade não me é dada de fora, pois, a dúvida rejeitara todo conhecimento por mim herdado. A verdade será alcançada por uma constatação própria de reflexão.

Se há um gênio maligno que sempre nos engana, então nós existimos porque ele nos engana. Cogito ergo sum, que, traduzido do latim para o português, diz: penso, logo, existo. Se pensamos que alguém nos engana, então existimos porque pensamos que alguém nos engana. A existência de nós mesmos, enquanto pensamento, é verdadeira. Mesmo com a dúvida mais exagerada, não conseguimos duvidar da nossa existência. Daí, 
REVISTA ALAMEDAS

Vol. 9, n. 2, 2021

e-ISSN 1981-0253

Descartes se pergunta qual tipo de existência lhe é assegurada como verdade, cuja resposta é: existo como pensamento. Portanto, chegamos a uma primeira noção de pensamento em Descartes: a noção de nossa própria existência. Nós existimos pensando. Nós existimos como pensamento. Isso não pode ser colocado em dúvida e, portanto, é verdade. Tais reflexões levaram à conclusão de que a essência do ser humano é ser pensante.

De um modo puramente didático, nos damos o direito de aqui fornecermos um exemplo lúdico de como reconhecemos, mesmo cotidianamente, o ser humano como ser pensante. Quando assistimos a um desenho em que o protagonista é uma esponja do mar ou um pica-pau, por que os tomamos como sujeitos, como "pessoas"? Ora, porque eles expressam pensamentos. É uma existência pensante que nos caracteriza como seres humanos.

Tomar o humano como ser pensante não diz muito por si mesmo. O que Descartes entende por pensamento?

\footnotetext{
[Princípios da Filosofia, primeira parte, artigo 9:] o que é pensamento: Pelo termo "pensamento" entendo todas aquelas coisas que, estando em nós conscientes, ocorrem em nós, na medida em que há em nós uma consciência delas. E assim, não apenas entender, querer, imaginar, mas também sentir é aqui o mesmo que pensar. Pois, se eu disser: "eu vejo" ou "eu ando, logo existo" e entender isso da visão ou do andar, que se realizam com o corpo, a conclusão não é absolutamente certa, visto que, como muitas vezes ocorre nos sonhos, posso presumir que estou vendo ou andando, ainda que não abra os olhos e não saia do lugar e, talvez, até mesmo, ainda que não tenha um corpo. Mas, se eu entender isso do próprio sentido ou da consciência de ver ou de andar, ela é inteiramente certa, porque se refere neste caso à mente, que é a única a sentir ou pensar que está vendo ou andando (DESCARTES, 2002, p. 29 , grifo posto).
}

De maneira geral, podemos tomar por pensamento tudo o que ocorre em nós de modo que somos imediatamente conscientes. Assim, o movimento não é um pensamento, tendo em vista que, v.g., não somos conscientes das batidas do coração que ocorrem em nós. Escutá-las ou prestar atenção nelas nos dá consciência de que as percebemos ou as sentimos elas. Nós percebemos o movimento quando notamos algo mudar de um lugar para outro, ou sentimos o movimento quando o vento esbarra em nosso corpo, mas em nosso pensamento as coisas não mudam de lugar porque um pensamento não ocupa espaço. Os movimentos, como rigorosamente Descartes compreende, i.e., movimento locativo, não ocorrem em nós, ocorrem à nossa volta. Lembramos que, para nos 
REVISTA ALAMEDAS

Vol. 9, n. 2, 2021

e-ISSN 1981-0253

desacostumarmos a dar crédito às coisas que recebemos dos sentidos ou dos ensinamentos de nossa cultura irrefletida, temos que nos apoiar apenas em evidências racionais. Quando ouvimos as batidas do coração, v.g., não temos certeza de que temos um corpo de onde elas vêm, pois podemos estar sonhando com elas. E, se daqui a pouco acordarmos e formos só um cérebro num tanque, sem corpo algum? ${ }^{4}$ Como não temos evidências racionais de ter um corpo $^{5}$, permanecemos apenas adotando a tese de que somos evidentemente pensamento: "concebo clara e distintamente que o eu pode subsistir sem o corpo, portanto concebo o eu como uma coisa completa [...], sem o corpo, e desse modo concebo que a corporeidade não pertence à natureza do eu" (SCRIBANO, 2007, p. 60$61)$.

Inegável, agora, nos parece ser a dúvida a respeito da origem de nossos pensamentos. Por meio de argumentos, demonstramos apenas a nossa própria existência enquanto pensamento. Mas, é inegável que temos ideias de muitas coisas. O que são as ideias? De onde elas vêm? Elas correspondem a algo existente ou existimos sós no mundo? Ou, melhor, tudo existe apenas como pensamento nosso ou existem coisas fora do nosso pensamento? Esta pergunta instaura o que no cartesianismo é chamado "verdade por correspondência": como podemos ter certeza de que existe algo fora do nosso pensamento quando temos acesso apenas ao que pensamos?

\section{PENSAMENTO COMO REPRESENTACIONAL: ASPECTOS DA IDEIA}

Podemos afirmar que o pensamento tem pensamentos. Pensar é ter pensamentos. Ao nos propomos distinguir a noção de pensamento em Descartes, temos em vista o pensamento que tem pensamentos, e não os pensamentos do pensamento. Inobstante, compreender como os pensamentos são presentificados (trazidos como que presentes) no pensamento nos ajuda a entender sua própria natureza. Isso porque as ideias têm o mesmo nível de certeza que o cogito: "se consideradas em si mesmas e não referidas às coisas a que se reportam, não podem ser propriamente falsas” (DESCARTES, 2018, p. 75).

\footnotetext{
${ }^{4} \mathrm{O}$ argumento do cérebro em um tanque está disponível no conto de número 38 , nomeado "eu sou um cérebro" (cf. BAGGINI, 2006, p. 119-120). Você pode ler o texto online em https://issuu.com/thiagodelaide/docs/o_porco_fil_sofo__ julian_baggini.

${ }^{5}$ Como você prova que seu corpo existe? A prova de Descartes precisa ter caráter argumentativo, racional. Que argumento racional usaria para provar que seu corpo existe, sem recorrer a qualquer um dos seus sentidos?
} 
REVISTA ALAMEDAS

Vol. 9, n. 2, 2021

e-ISSN 1981-0253

Dizemos que, em Descartes, cada um de nossos pensamentos se reporta a algo quando ele representa algo, quando ele apresenta algo para a consciência. "Representar é apresentar no pensamento um conteúdo determinado (uma res)" (LANDIM, 1992, p. 33). O pensamento que temos acerca de uma pedra não é o mesmo que a pedra. Enquanto a imagem da pedra é trazida diante de nós por meio do pensamento, temos da pedra uma representação. No português, pouco usamos o termo "presentar". Em seu lugar, usualmente expressamos "apresentar" no sentido de "presentar", e o uso do "a" antecedendo o termo principal não gera negativa dele como, v.g., o caso de "normal/anormal". Cientes de que "apresentar" e "presentar" são sinônimos, acrescemos ao "presentar" o prefixo de repetição "re" para formarmos o termo "representação". Ora, se a pedra é presentada diante dos olhos, a luz que reflete da pedra na retina produz no pensamento a representação da pedra. A representação, em sentido lato e tomando a palavra em seu sentido literal, é presentar em lugar de. O pensamento que temos da pedra é a duplicação de sua imagem, uma vez que a imagem da pedra está disponível para qualquer um que a veja enquanto que nosso pensamento da pedra é apenas nosso.

A representação ganha daí o sentido de subjetiva ou interior porque as ideias são pensamentos. O fato de que os nossos pensamentos não estão acessíveis a qualquer um, senão por meio de nossas expressões físicas, faz com que o pensamento seja abordado como interioridade. O pensamento é o único capaz de se deparar consigo mesmo (cf. BATISTTI, 2010, p. 127). Nossos pensamentos estão encapsulados numa atmosfera que representa coisas em que pensamos. Nosso pensamento é representacional. Ele tem presente diante de si a imagem de coisas que ele não é. Pensar é sempre pensar sobre algo. Essa oposição entre o pensamento e as coisas das quais ele tem ideias é tomada sob a forma que nomeamos acima de verdade por correspondência. Antes de tratarmos desse tema, queremos apontar importantes aspectos do pensamento como representação.

Tomar o pensamento como representacional, i.e., como aquele que tem coisas presentadas diante de si que não são por ele produzidas, significa tomar a representação como uma impressão causada por algo diferente dele. O sentido de interioridade e de exterioridade se determina segundo a origem dos eventos que ocorrem no pensamento. Tudo o que ocorre na esfera do pensamento é tomado como evento interior. O que não tem sua origem do próprio pensamento é tomado como exterior. Mesmo que uma representação ocorra no pensamento, sua origem pode ser no próprio pensamento ou não. 
REVISTA ALAMEDAS

Vol. 9, n. 2, 2021

e-ISSN 1981-0253

Dizemos que a alegria e a tristeza, e.g., são tomadas como oriundas do próprio pensamento porque não as recebemos dos nossos cinco sentidos. Tudo o que nos é tomado como exterior ao pensamento tem origem em nossos cinco sentidos, e.g., as cores, os sons.

Tomar as representações como oriundas do nosso interior ou do nosso exterior é tomar toda representação como sendo o efeito de algo. Tudo o que nos é representado no pensamento tem uma causa. Rastrear a causa de nossas representações é o meio que Descartes se propõe a colocar o problema da verdade por correspondência. Como sabemos que a origem de nossas representações é algo real? Ao compormos uma imagem qualquer mesclando elementos que à mercê de nosso gosto é um exemplo claro de algo que não seja real independentemente de meu pensamento. Se algo que penso depende de meu pensamento e permanece na esfera dele, então dizemos que esse algo é real apenas enquanto pensamento meu. Por outro lado, se algo se impõe a meu pensamento e nele causa uma impressão independentemente dele, então esse algo existe fora do pensamento, e não apenas enquanto representação dele.

$\mathrm{Na}$ esfera da dúvida metódica, o pensamento é um fato que se impõe mesmo às nossas mais esdrúxulas representações. Não conseguimos duvidar da sua existência. O nosso próprio pensamento não é uma representação do nosso pensamento, mesmo quando pensamos sobre ele. Pensar em nosso pensamento pode ser feito por meio de uma representação dele, mas não conseguimos tomá-la como mera representação, pois vimos que a representação é o presentar repetido de algo. Portanto, a origem da representação do pensamento enquanto pensamos é o próprio pensamento que pensa tal representação. Ele corresponde à representação de si.

As representações têm três gêneros de origens. São as (1) ideias adventícias, as (2) ideias fictícias e as (3) ideias inatas. As (1) ideias adventícias são aquelas representações que parecem nos vir de fora, por meio dos nossos cinco sentidos. As (2) ideias fictícias são composições que fazemos a bel prazer, e.g., quando imaginamos nosso cabelo de outra cor. As (3) ideias inatas são as representações que já nascem conosco, v.g., a representação de unidade, de figura, de extensão. Sobre as (3) ideias inatas recaem as reflexões de Descartes, e é por defendê-las que o tomam como racionalista. É importante entendermos dois aspectos delas: elas estão em nós desde sempre, portanto, pertencem à nossa constituição. Além disso, embora inatas, elas têm origem fora de nós. 
REVISTA ALAMEDAS

Vol. 9, n. 2, 2021

e-ISSN 1981-0253

Estão em nossa composição desde sempre, mas não as criamos porque não criamos a nós mesmos. Fomos criados por outro ser. Do contrário, poderíamos nos recriar a todo instante e seríamos eternos. Como fomos criados por outro ser, então as ideias inatas advêm daí .

\section{PERCEPÇÃO CLARA E DISTINTA}

O pensamento como representacional implica a percepção de ideias. Perceber é conscientizar de algo que se presenta diante de nós. Isso ocorre sobre a base representacional, que dá o sentido de sujeito ou de objeto às representações percebidas. Se percebemos uma pedra, então a tomamos como objeto de nosso conhecimento ao mesmo tempo em que tomamos a nós próprios como sujeitos desse conhecimento. Determinar a pedra como representação é determinar a imagem dela presentada em nosso pensamento, portanto, é determinar a nós próprios como sujeitos desse pensamento. Para que uma representação seja verdadeira, ela deve ser fidedigna aos limites do conhecimento, i.e., a imagem deve corresponder adequadamente ao modo de esse conhecimento se constituir. Daí, surge a noção de percepção clara e distinta.

A percepção clara é a percepção que nos é nítida, "aquela que está manifestamente presente a uma mente atenta" (DESCARTES, 2002, p. 61). A percepção clara é oposta à percepção obscura. Se tomarmos a tradução ao pé da letra, "obscuro", que significa "sem luz", remete à luz da razão que Descartes menciona repetidas vezes em sua obra

\footnotetext{
${ }^{6}$ As ideias inatas podem ser definidas por aquilo que elas não são. As ideias inatas não são as ideias oriundas de nossos cinco sentidos nem são as ideias que nós mesmos compomos. Deste modo, nos parece lúcido aderir ao inatismo da ideia de unidade, por exemplo. Quando conseguimos destacar algo como a frente da diversidade em que está colocado, e.g., quando vemos uma pessoa que conhecemos entre um grupo de pessoas, temos a ideia de unidade que não pode ser oriunda da nossa visão. Quando ouvimos a melodia de uma música, não a destacamos da harmonia ou do ritmo com o ouvido. A ideia de unidade nos parece inata. Assim, também vemos os objetos com este ou aquele formato, mas a ideia de figura não nos parece vir do tato ou da visão. Portanto, só podem, ideias assim, nos serem inatas. $\mathrm{O}$ segundo aspecto ligado às ideias inatas é notá-las sob a esteia da causalidade. Tendo em mente que tudo o que nos aparece, nos aparece como efeito, é de se perguntar a origem das ideias inatas. A maioria delas parece ter origem em nossa própria constituição, como apontamos acima. Mas, ideias como a de eternidade, de infinitude e de perfeição parecem deslocadas de nossa constituição pelo simples fato de que não temos essas qualidades em nós mesmos. Se somos finitos, e.g., de onde temos a ideia de infinitude? Ora, partindo do pressuposto de que a infinitude não se dá pela soma de todas as finitudes, concluímos que a ideia de infinitude só pode ter feito parte de nossa constituição se colocada em nós por alguma entidade que tenha em si mesma tal qualidade. Assim, Descartes prova a existência de Deus e tira o pensamento humano de um solipsismo. A ideia de Deus como perfeito, eterno e infinito também tolhe o argumento do Deus enganador porque a atitude de enganar denuncia uma impotência ou imperfeição, já que se posso algo, não recorro a artimanhas à sua conquista.
} 
REVISTA ALAMEDAS

Vol. 9, n. 2, 2021

e-ISSN 1981-0253

metafísica capital. Entendemos então como obscuras aquelas ideias sobre as quais a razão não lança sua luz abertamente. Se pensarmos no valor exato do número $\pi$, teremos apenas uma percepção obscura, uma vez que ele contempla numeral indefinido. Já a percepção distinta é aquela que não se confunde com outra. "Além de ser clara, é tão precisamente separada das outras que absolutamente nada mais contém em si além do que é claro" (DESCARTES, 2002, p. 61). Um exemplo: conscientizarmo-nos de que existimos enquanto pensantes é distinto de tudo o mais. Mesmo que julguemos outros como pensantes, só nós nos conscientizamos de que nós somos pensantes. Isso nos é distinto, ninguém pode se conscientizar por nós de que somos pensantes. Aliás, é do axioma cogito ergo sum que Descartes elabora tais características de uma percepção verdadeira. Se algo nos aparece clara e distintamente, podemos o tomar como verdadeiro ${ }^{7}$.

Clareza e distinção são os requisitos de uma percepção verdadeira, i.e., uma representação que se adequa aos limites do conhecimento humano. Significa dizer que toda representação clara e distinta tem seu objeto como correspondentemente existente fora do pensamento. Como a noção de percepção clara e distinta é extraída da sentença cogito ergo sum, nos parece lícito colocar que ela determina o sujeito do conhecimento enquanto existente. Ao fazer isso, no âmago da dúvida metódica, tudo o mais será adequado à essa primeira verdade. A verdade por correspondência é a correspondência entre as determinações do sujeito do conhecimento e as determinações do objeto do conhecimento no âmbito representacional. A existência dos entes se dá por verdadeira quando couberem nas vestes determinativas do sujeito do conhecimento. Essa transposição ou replicação das determinações do sujeito do conhecimento ditam as determinações em que o objeto vestirá para ser calibrado como verdadeiro existente. A ideia clara e distinta de Deus e a ideia clara e distinta da extensão serão representações adequadas às determinações do sujeito do conhecimento no âmbito da metafísica cartesiana. Serão, sobretudo, percepção de representações claras e distintas. E, embora ela, a metafísica de Descartes, sirva de raízes ao fazer científico, guiando a experiência por meio dos axiomas da razão, ela intenta manter os objetos do conhecimento sob os limites da natureza do conhecimento humano, que, entendemos, é representacional.

\footnotetext{
${ }^{7}$ Cabe observar que nem sempre que uma percepção seja clara, ela também seja distinta. O artigo 46 dos Princípios da Filosofia traz o exemplo da dor, em que nos é clara a ideia da dor, mas não distinta, pois, embora seja, v.g., em nosso braço, não sabemos exatamente de onde ela procede. A percepção distinta, no entanto, é sempre clara também.
} 
REVISTA ALAMEDAS

Vol. 9, n. 2, 2021

e-ISSN 1981-0253

A percepção clara e distinta é também a percepção do objeto em sua simplicidade (cf. GUÈROULT, 2016, p. 40). Clareza e distinção, no fundo, denotam um elemento simples do conhecimento humano (cf. MARION, 2009, p. 161). A ordem que Descartes defende em seu método é a ordenação aparentemente linear que vai dos elementos simples aos elementos compostos. Podemos entender como simples aquilo que não pode ser extraído do conceito de algo sem que o desconfigure. A simplicidade, sob esse aspecto, traz ao fundo um vínculo de dependência entre os conhecimentos humanos, em que o mais simples é também o mais absoluto. Deus é mais simples que o homem. O homem é um objeto composto para o conhecimento, uma vez que ele trata da união entre duas coisas simples, i.e., o homem é a fusão entre corpo e pensamento (SKIRRY, 2010, p. 168 e ss.). Nesse sentido, a percepção clara e distinta é a percepção calibrada que reduz ao máximo a ideia de algo sem perder sua natureza.

A obra Regras para a orientação do espírito, obra póstuma de Descartes, publicada incompleta, trazia a noção de naturezas simples. As naturezas simples são ideias de uma só propriedade. Várias noções ajudam a compô-las, mas nelas reside apenas uma propriedade. A ideia de figura, e.g., traz as noções de limite e de extensão, mas nenhuma dessas a define como propriedade que lhe é natural, i.e., que se extirpada dela, arranca também sua natureza distinta (cf. DESCARTES, 2007, p. 82). Limite e extensão são noções por demasiado genéricas para distinguir a ideia de figura de outras ideias. Por nada mais conseguir definir a figura tal e qual ela é percebida pelo pensamento, ela é uma natureza simples. Uma natureza simples é uma ideia de uma só propriedade. Uma ideia de uma só propriedade é uma percepção distinta. Uma percepção distinta é também uma percepção clara. Portanto, a percepção clara e distinta é a percepção calibrada, que ajusta as determinações do objeto às determinações encontradas no sujeito do conhecimento, suportado no ambiente representacional.

\section{PAIXÕES, IMAGINAÇÃO, MEMÓRIA E SENSAÇÕES}

Os limites do conhecimento humano são dados por Descartes no âmbito representacional em que sujeito e objeto deixam suas determinações corresponderem fidedignamente. Se tomado sob essa perspectiva, diz Descartes, encontraremos a verdade porque filosofaremos por ordem, tomando primeiro as primeiras coisas (cf. 
REVISTA ALAMEDAS

Vol. 9, n. 2, 2021

e-ISSN 1981-0253

DESCARTES, 2003, p. 4). O fato é que algumas representações podem advir de alhures à razão humana, i.e., da capacidade de enumerar as determinações das representações percebidas do simples ao composto. Se tomarmos uma representação pela via diversa da razão, podemos apreender uma percepção confusa (contrária à percepção distinta). Ocorre quando tomamos a ideia dos objetos a partir das sensações. Sabemos que, espelhada aos limites do sujeito do conhecimento, a percepção distinta dos objetos materiais é destituída de cores, tamanhos, pesos. Se recepcionarmos uma ideia por meio das sensações, temos a ideia confusa, pois a ela mesclamos inevitavelmente nossas impressões corpóreas do objeto material, e não a compreenderemos pela purê fonte do entendimento humano, fonte da qual verdadeiramente provêm nossos conhecimentos.

No entanto, as vias distintas da razão podem auxiliar o conhecimento. A imaginação é um recurso que pode auxiliar a razão na busca da verdade (cf. BUZON; KAMBOUCHNER, 2010, p. 45-46). A entendemos como a capacidade de conceber imagens. A imagem tem um sentido amplo no pensamento de Descartes, pois trata de qualquer representação oriunda das sensações. Quando desenhamos um triângulo, concebemos mais facilmente uma figura de três lados, embora a representação de triângulo não precise ser imagética. Um hectágono - polígono com cem lados - ou um quilógono - polígono com mil lados - não são fáceis de serem imaginados, mas podem ser representados facilmente por nosso entendimento, mesmo sem recorrer à imagem. Enfatizamos, com esse exemplo, que uma representação não precisa ser imagética. Podemos ter a representação de uma vontade, por exemplo. Assim, ocorre também com os números, cuja representação gráfica não os define, mas auxilia o entendimento em cálculos ou apontamentos quantitativos. O mesmo ocorre com as palavras, que pronunciadas, a rigor, não passam de movimentações do ar que atingem nossos tímpanos (cf. COMINETTI, 2013, p. 67 e ss.). Elas são modulações que nos representam ideias, mas jamais passam de representações imagéticas que auxiliam o entendimento, como quando, e.g., descobrimos acerca de nós próprios ao escrever sobre uma situação vivenciada. Acreditamos que não é preciso mencionar o auxílio da memória em nossos processos intelectuais ${ }^{8}$.

\footnotetext{
${ }^{8}$ A memória é compreendida como memória física e memória intelectual. A memória física é uma espécie de tela alocada no interior do cérebro humano onde são impressos pequeninos furos que configuram uma imagem. Conforme é reiterada, os furos se salientam e podem ser acessados mais facilmente. A memória intelectiva é menos descrita por Descartes, mas parece versar acerca de conteúdos exclusivamente 
REVISTA ALAMEDAS

Vol. 9, n. 2, 2021

e-ISSN 1981-0253

As paixões tratam de um aspecto ligeiramente diferenciado com relação aos demais. Divididas entre paixões da alma e paixões em geral, são afetações no pensamento (SKIRRY, 2010, p. 192 e ss.). Fome, dor e calor são exemplos de paixões ligadas ao composto corpo e alma, em que o pensamento é afetado por variações que o corpo a ele mesclado sofre. Paixões como alegria e desejos são paixões que não nos são oriundas do corpo porque os sentidos não são causas delas. Sobretudo, nos interessa pontuar que as paixões, enquanto afetações no pensamento, não são relevantes, em Descartes, para o fazer científico. Frequentemente, a noção de pensamento é dada pela obra metafísica de Descartes. Nela, o autor visa fundamentar a ciência. O tema das paixões é tomado como tema marginal à fundamentação da ciência. As paixões afetam o pensamento por serem estados de humor conscientes - e tudo o que ocorre em nós, na medida em que temos consciência dessa ocorrência - mas não devem ser tomados como fundamento das ciências porque têm natureza composta: elas provêm do sentir, pensamento afetado pelo corpo. Mesmo as paixões da alma são pensamentos que alteram estados do organismo, e embora não venham deles, não se tornam centro da discussão do fazer científico na obra cartesiana.

\section{VONTADE E PERCEPÇÃO COMO MODOS GERAIS DE SER: JUÍZOS}

As paixões são percepções do pensamento. Elas são percebidas. Afetam o pensamento. Por outro lado, são pensamentos, representações, pois são conscientes. Essa discussão nos leva a abordar o pensamento sob um duplo aspecto: passivo e ativo. "Todos os modos de pensar que experimentamos em nós podem ser referidos a dois gerais, dos quais um é a percepção ou a operação do entendimento, o outro, porém, a volição o a operação da vontade" (DESCARTES, 2002, p. 51). O aspecto passivo do pensamento é o aspecto representacional que ele apresenta, o aspecto perceptivo. A percepção é passiva no sentido de que ela não governa os conteúdos que recebe (cf. ALQUIÉ, 1993, p. 84). Mesmo as imaginações são compostas a partir de realidades inalteráveis, resistentes à influência ativa do pensamento. A atividade do pensamento é oposta à percepção e chama vontade. A vontade do pensamento é seu aspecto ativo no sentido de que o pensamento

imateriais, tais como uma cadeia dedutiva de longo argumento pode ser suprimida se nos lembrarmos como as expressões iniciais estão vinculadas às recentes. 
REVISTA ALAMEDAS

Vol. 9, n. 2, 2021

e-ISSN 1981-0253

se move em direção a algo. Querer ou não querer algo é exemplo da vontade, pois aí o pensamento se comporta em direção a algo.

A percepção é tida como o aspecto mais essencial do pensamento porque está presente de modo mais íntimo à sua natureza. Na atuação da vontade, algo deve ser percebido para ser desejado. Também, a própria vontade pode ser percebida, desde que tenhamos dela consciência como algo apartado do seu objeto. O querer algo tem conteúdo distinto do algo que se quer, e ambos podem ser representados no pensamento. Inobstante, a vontade tem o caráter de infinitude. Nosso querer é insaciável e pode mesmo lançar o pensamento para além das percepções. Isso ocorre quando, e.g., afirmamos algo sem aterse à sua pura representação. A vontade pode apreender percepções confusas como distintas, pois dada sua insaciedade, ela pode facilmente transbordar as representações. Essa é fonte de erro, em Descartes, "pois podemos assentir a muitas coisas que não conhecemos senão de maneira muito obscura e confusa" (DESCARTES, 2002, p. 51).

$\mathrm{O}$ erro em nossos julgamentos ocorre porque deixamos que a vontade transborde as percepções que temos. Toda vez que afirmamos ou negamos algo, expressamos deliberadamente o valor sobre uma percepção. Se afirmamos que o cogito é verdadeiro, formulamos um juízo sobre o cogito. Essa afirmação tem a natureza de uma vontade porque afirmar algo como verdade é querer buscar ou expressar algo como certo. Assim, a vontade está valorando a percepção, categorizando-a, agregando-lhe algo. Se mantivermos a vontade sobre os estreitos limites de nossas representações e afirmarmos apenas suas naturezas simples enredadas por noções comuns, então teremos um discurso adequado às percepções fixas e duradouras que a luz natural nos revela. Atribuiremos valor de verdade à coisas claras e distintas. Encontraremos o que é indubitável. Do contrário, nossas afirmações cairão no campo vasto da incerteza ${ }^{9}$. O conhecimento, em Descartes, tem aspecto passivo porque a verdade só pode ser contemplada, jamais construída a partir da vontade do sujeito.

\section{SUBSTÂNCIA, ATRIBUTO E MODOS}

\footnotetext{
${ }^{9}$ Há uma discussão que, embora marginal, nos pareça pertinente de menção: se a vontade é infinita, como ela está alocada em um ser finito? Sobre a discussão, Gueroult e Laporte têm opiniões distintas. Guèroult (cf. 2016, p. 189) aponta que a vontade, e.g., não comporta realidade objetiva porque não trata de uma representação. Laporte (cf. 2000, p. 125), em sentido ligeiramente diferente, ao tomar a infinita liberdade humana como a marca da infinitude divina, toma a liberdade como representação da qual poderíamos inferir a existência de Deus.
} 
Além das perspectivas da atividade ou da passividade do pensamento, há uma hierarquização de suas perspectivas discutidas por Descartes (cf. ALQUIÉ, 1993, p. 81 e ss.). Como percebemos o pensamento como uma coisa que depende única e exclusivamente do concurso de Deus para existir, então o tomamos como uma coisa independente. Do ponto de vista geral, Deus é a única coisa da qual todas as demais dependem e, rigorosamente falando, é a única coisa existente que é realmente independente de tudo o mais (cf. BEYSSADE, 1997). Por isso, o sentido próprio do termo substantia é concernente apenas à substância criadora infinita. Por outro lado, podemos nos referir ao pensamento como uma substância se tomarmos o termo de maneira análoga àquela usada para denotar a natureza divina. $\mathrm{O}$ pensamento é substância em sentido análogo àquele usado par anos referirmos à verdadeira substância, Deus. Podemos tomar esse sentido análogo porque o pensamento não depende de nada mais além de Deus para se conservar como tal.

Por ser uma coisa realmente existente, a substância pensamento tem uma propriedade exclusiva que a distingue de todas as outras substâncias. Essa propriedade é chamada de pensamento, e é caracterizada como o atributo principal da substância que estamos a tratar. Antes que haja confusão entre substância e pensamento, devemos apontar que eles são distintos um do outro apenas de maneira didática, i.e., são vistos como coisas diferentes apenas sob o ponto de vista teórico instrutivo (cf. DESCARTES, 2002, p. 79-81). Em verdade, se notarmos o pensamento como uma unidade, o veremos como uma substância. Do mesmo modo, se vemos uma coisa qualquer, podemos perceber os atributos que a caracterizam. Assim, substância e pensamento não podem ser coisas diferentes que estão mescladas, mas uma só coisa inseparável. O termo substância quer indicar unidade de algo independente. O pensamento é o atributo principal dessa unidade, que a caracteriza e denuncia sua natureza (cf. DESCARTES, 2002, p. 69).

Assim como o atributo principal revela a substância à qual pertence - que Descartes chama substância pensante ou res cogitans -, os modos em que esse atributo principal, chamado pensamento, se modula, deixam ver suas manifestações como umas distintas das outras. Se, e.g., duvidamos ou queremos algo, então o pensamento enquanto atributo principal se apresenta como dúvida, num momento, e como querer, em outro. Às modulações possíveis do pensamento, Descartes chama modos (cf. DESCARTES, 2002, 
REVISTA ALAMEDAS

Vol. 9, n. 2, 2021

e-ISSN 1981-0253

p. 71). Os modos do pensamento são todas as suas manifestações, comportamentos, expressões, tudo aquilo que, presente na substância pensante, a faz como tal. Um pensamento não tem figura nem ocupa espaço, por exemplo, porque esses não são modos de ele existir. A substância pensante está limitada às modulações de seu atributo principal, pois é substância atribuída a ele enquanto propriedade percebida. O pensamento pode se modular como dúvida, como representação, como querer, como paixão, como entendimento, como imaginação, etc.

\section{CONSIDERAÇÕES FINAIS}

A noção de pensamento em Descartes deve ser tomada imprescindivelmente sob dois aspectos. Ela deve ser entendida como uma noção que visa atender ao problema do conhecimento humano. Nisso, não pode ser confundida com a fala leviana do cotidiano que pretender tomar como pensamento algo genérico ou aplicável a tudo. Por isso, nossa primeira caracterização do termo foi a de mostrar como o entendimento deve ser apartado da sensação, da memória e da imaginação. O núcleo de o que Descartes entende por pensamento se concentra no entendimento.

Em seguida, tomamos o pensamento como representacional ao caracterizá-lo como algo que forma a ideia das coisas. Com a nossa abordagem do tema, quisemos refutar a opinião do populacho que afirma ser o pensamento cartesiano uma espécie de recipiente em que os conteúdos do mundo são depositados. As representações são enformes dado pelo pensamento às coisas que toma como objetos do entendimento. Quisemos mostrar como o pensamento atua na apreensão dos conteúdos de uma maneira representativa, espelhando em si as imagens das coisas corpóreas ao elaborar representações de propriedades quaisquer, materiais ou não. Essa característica do pensamento pode mesmo ser abordada como seu modo principal de atuação, já que ele enforma todo objeto que se torna perceptível em sua esfera representativa.

Se a representação é a única maneira de o pensamento perceber algo, i.e., se o pensamento percebe apenas suas representações, a percepção das representações é a característica de o pensamento se ver afetado por impressões. Por isso, a percepção tem um aspecto passivo na noção de pensamento em Descartes. Assim, o próprio conhecimento, que só se dá por representações, tem um aspecto passivo em Descartes, no 
REVISTA ALAMEDAS

sentido de que a verdade só pode ser contemplada, e jamais elaborada à mercê da vontade humana.

A verdade precisa ser descoberta, não criada. A criação tem o aspecto de composição, e é o que caracteriza o aspecto ativo do pensamento, a que Descartes chama vontade. A vontade é infinita, pois insaciável, ilimitada, enquanto que a percepção é limitada. Assim, a natureza do próprio conhecimento humano se faz limitada, uma vez que só se pode conhecer o que se percebe como necessário e irredutível à percepção humana. Os juízos que se propõe agregar conhecimento devem, portanto, ser afirmados ou negados com base na estrita percepção das representações despidas de composição. Apenas o entendimento deve operar no desvelamento da verdade. Ele deve encontrar as naturezas simples, que são ideias de uma só propriedade, e enredá-las umas às outras por meio de noções comuns, vínculos necessários que Descartes nomeia de axiomas da razão.

Por fim, apontamos a nomenclatura da qual Descartes se serve para dar uma visão mais detalhada de como entende o pensamento enquanto coisa pensante (res cogitans). Chamar o pensamento de "coisa" lhe atribui o sentido de independência, e isso poderia mesmo ter consequências repercutidas em outros campos que não o do conhecimento. Aí estaria, v.g., uma deixa para que interessados justificassem a imortalidade da alma. Em Descartes, o pensamento não emerge do organismo humano, como quiçá do cérebro. $\mathrm{O}$ imaterial não emerge da matéria. Tomar o pensamento como coisa é dizer que sua natureza é de tal modo distinta da natureza corpórea que em tudo se distinguem. Atentos ao axioma da causalidade, sabemos que do nada, nada vem. Como poderia a matéria gerar a imatéria se naquela não estão presentes as propriedades da imatéria? Assim, a coisa pensante tem apenas um atributo principal, o pensamento, e ele se deixa modular de várias maneiras. O pensamento existe sob vários modos de ser. Esses são chamados modos.

A noção de pensamento em Descartes não está esgotada em nenhuma de suas obras. Precisamos reconstituí-la articulando seus escritos de uma maneira coerente, interpretando as passagens umas ao lado das outras. Nessa tarefa, nos parece crucial não perder de vista o horizonte em que Descartes aloca esse conceito: a noção de pensamento é a noção de pensamento científico. Ele pode ser aplicado aqui ou ali de maneira genérica e despropositada. Podemos entender que o pensamento não pode ser dividido entre entendimento, imaginação e memória, mas apenas caracterizado como funcionando deste ou daquele modo, pois é indivisível. No fim, interessa evitar o anacronismo de extirpar a 
REVISTA ALAMEDAS

Vol. 9, n. 2, 2021

e-ISSN 1981-0253

filosofia de Descartes do ambiente que lhe fomentou: o início da modernidade científica, a derrocada da influência política sobre o fazer científico e a busca por um método que conduzisse o homem à contemplação da verdade (cf. GAUKROGER, 1999, p. 21 e ss.).

\section{REFERÊNCIAS BIBLIOGRÁFICAS}

ALQUIÉ, Ferdinand. A filosofia de Descartes. Tradução de M. Rodrigues Martins. Lisboa: Editorial Presença, 1993.

BAGGINI, Julian. O porco filosófico: 100 experiências de pensamento para a vida cotidiana. Tradução de Edmundo Barreiros. Rio de Janeiro: Relume Dumará, 2006.

BATTISTI, César Augusto. Sujeito em Descartes: ser pensante e corpo. In: BATTISTI, César Augusto. Às voltas com a questão do sujeito: posições e perspectivas. Ijuí/RS: Ed. Unijuí; Cascavel: Edunioeste, 2010.

BEYSSADE, Jean-Marie. A teórica cartesiana da substância: equivocidade ou analogia? Ano de $1997 . \quad$ Disponível em https://revistas.ufrj.br/index.php/analytica/article/view/410.

BUZON, Frédéric de. KAMBOUCHNER, Denis. Vocabulário de Descartes. Tradução de Claudia Berliner. São Paulo: Editora WMF Martins Fontes, 2010.

COMINETTI, Geder Paulo Friedrich. A noção de linguagem em Descartes: ensaio sobre o conceito de linguagem na filosofia dualista de René Descartes. Toledo/PR: [s.n.], 2013. Disponível em http://tede.unioeste.br/handle/tede/2052.

DESCARTES, René. Carta-Prefácio dos princípios da filosofia. Tradução de Homero Santiago. São Paulo: Martins Fontes, 2003.

DESCARTES, René. Discurso do método \& ensaios. Organizado por Pablo Rubén Mariconda; traduzido por César Augusto Battisti, Érico Andrade, Guilherme Rodrigues Neto, Marisa Carneiro de Oliveira Franco Donatelli, Pablo Rubén Mariconda, Paulo Tadeu da Silva. São Paulo: Editora Unesp, 2018.

DESCARTES, René. Meditações sobre filosofia primeira. Tradução: Fausto Castilho. Edição bilíngue em latim e português. Campinas, SP: Editora da Unicamp, 2018. ( $3^{\text {a }}$ reimpressão)

DESCARTES, René. Regras para a orientação do espírito. Tradução de Maria Ermantina de Almeida Prado Galvão. São Paulo: Martins Fontes, 2007.

FORLIN, Enéias. A teoria cartesiana da verdade. São Paulo: Associação Editorial Humanitas; Ijuí: Editora Unijuí/Fapesp, 2005.

GAUKROGER, Stephen. Descartes: uma biografia intelectual. Tradução: Vera Ribeiro. Rio de Janeiro: EdUERJ: Contraponto, 1999. 
Filosofia

LANDIM FILHO, Raul Ferreira. Evidência e verdade no sistema cartesiano. São Paulo: Loyola, 1992.

MARION, Jean-Luc. A metafísica cartesiana e o papel das naturezas simples. Tradução de André Oídes. In: COTTINGHAM, John. DESCARTES. Aparecida/SP: Ideias \& Letras, 2009.

SCRIBANO, Emanuela. Guia para leitura das meditações metafísicas de Descartes. Tradução de Silvana Cobucci Leite. São Paulo: Edições Loyola, 2007.

SKIRRY, Justin. Compreender Descartes. Tradução de Marcus Penchel. Petrópolis/RJ: Editora Vozes LTDA, 2010. 